\title{
PENGARUH WAKTU PENGENDAPAN AIR BAKU BAK PRASEDIMENTASI DI IPA TIRTA KEUMUENENG PDAM KOTA LANGSA
}

\author{
Hijrahanisa \\ Jurusan Fisika, Teknik, Universitas Samudra \\ *Co-Author: $\underline{\text { hijrahanisa@gmail.com }}$
}

\begin{abstract}
Abstrak
Telah dilaksanakan penelitian di PDAM Tirta Keumeng Langsa dengan judul pengaruh waktu pengendapan air baku bak prasedimentasi Di IPA Tirta Keumeuneng PDAM Kota Langsa yang bertujuan untuk mengetahui waktu pengendapan air baku yang baik pada bak prsedimentasi serta mengetahui pengaruh kekeruhan air dan TDS terhadap waktu pengendapan air baku. Metode yang digunakan dalam penelitian ini yaitu metode studi lapangan yang meliputi pengamatan, peninjauan dan mempelajari secara langsung bagaimana pengaruh waktu pengendapan air baku dengan wak tu yang berbeda yaitu pada waktu 0, 5, 35- 125 menit. Proses pengendapan diambil dari intake untuk mengambilair dari sungai sebagai air baku y a ng dibutuhkan dan diangkut oleh pompa ke tempat prasidementasi. Dari penelitian yang telah dilaksanakan didapatkan ba hwa pengaruh waktu pengendapan terhadap kekeruhan dan TDS air baku mengalami penurunan. Karena kualitas air baku semakin lama waktu pengendapan maka kekeruhan air baku semakin baik yaitu saat waktu 120 menit dengan tin gkat kekeruhan sebesar 13,9 dengan TDS sebesar $90 \mathrm{Mg} / \mathrm{L}$. Berdasarkan baku mutu dan standar air minum PERMENKES No.492/Men.KES/PER/IV/2010 tingkat kekeruhan dan TDS air baku diperbolehkan maksimal 5 NTU dengan TDS y aitu $500 \mathrm{Mg} / \mathrm{L}$. Oleh karena itu penga matan ini diperlukan pengolahan lebih lanjut untuk layak digunakan .
\end{abstract}

Kata kunci: PDAM Tirta Keumueneng Langsa, air baku, waktu pengendapan, kekeruhan air dan TDS

\section{PENDAHULUAN}

Sumber daya a lam sangat penting da lam kehidupan masyarakat salah satunya adalah air. Air dari alam (air baku) y a ng digunakan tidak dapat di pakai secara langsung harus melalui proses pengolahan yang bertujuan agar air tersebut memenuhi standar air minum atau air bersih sehingga dapat dimanfaatkan. Kualitas air baku salah satu penentuan efisiensi pengola ha $\mathrm{n}$ yang terdapat faktor seperti kekeruhan, warna, $\mathrm{pH}$, kandungan zat kimia, dan sebagainya, maka dibutuhkan pada suatu intansi sesuai dengan kuantitas yang diinginkan [1].

Berkaitan dengan permasalahan PDAM (Perusahaan Daerah Air Minum) sebagai perusahaan pemerintah yang berfungsi menyediakan air bersih. PDAM juga berperan penting dalam melakukan pengolahan, penyediaan, dan penyaluran air bersih ke masyarakat. Air yang digunakan dari air baku sungai dengan kualitas air yang berubah dari waktu ke waktu akibat pengaruh lingkungan seperti cuaca dan iklim dan harus berkua litas saat disalurkan. Sebelum melakukan pen y alu ran maka airbaku sungai diolah terlebih dahulu a garkua litas air yang dimanfa atkan oleh ma sya rakat dala meadaan bersih [2]. Proses pengolahan air menggunakan beberapa unit diantaranya Intake, prasedimentasi, bangunan bahan kimia, koag ula si, dan Instalasi pada Pengolahan Air a tau disingkat dengan IPA. Pada IPA tersebut terda pat beberapa proses seperti flokula si, sedimentasi, filtrasi, dan Reservoir yang bertujuan untuk memenuhiair bersih yang dapat dimanfaatkan.

Selain itu, adanya bangunan penyadap air (Intake) yang merupakan tempat mengambilan air dari sungai untuk dimanfaatkan yang berfungsi untuk menjaga kestabilan debit bahan baku yang dibutuhkan. Kemudian akan di angkut dengan menggunakan pompa melalui pipa menuju ke prasedimentasi. Bangunan pengendap pertama (prasedimentasi) a ir yang berawal dari intake ditampung pada prasedimentasi berfungsi untuk menurunkan partikel-partikel dari air sungai menggunakan sistem gravitasi. Dari penjelasan di atas, saya akan melakukan penelitian dengan judul Pengaruh Waktu Pengendapan Air Baku Bak Prasedimentasi di IPA Tirta Keumueneng PDAM Kota Langsa.

\section{METODE PENELITIAN}

Metode yang digunakan yaitu metode studi lapangan yang meliputi pengamatan, peninjauan dan mempelajari secara langsung bagaimana airbaku menjadi air bersh yang layak digunakan dalam masyarakat. Proses pengambilan data penganuh waktu pengendapan air baku pada bak prasedimentasi dilakukan dengan beberapa tahapan. Tahapan-tahapan tersebut dimulai dari intake, bak prasedimentasi, pengambilan data, hasil data uji laboraturium yaitu analisis data turbidimeter (kekeruhan air) dan analisis data TDS ( jumlah zat terlarut). Tahapan tersebut da pat dilihat pada Gambar 1 dibawah ini. 


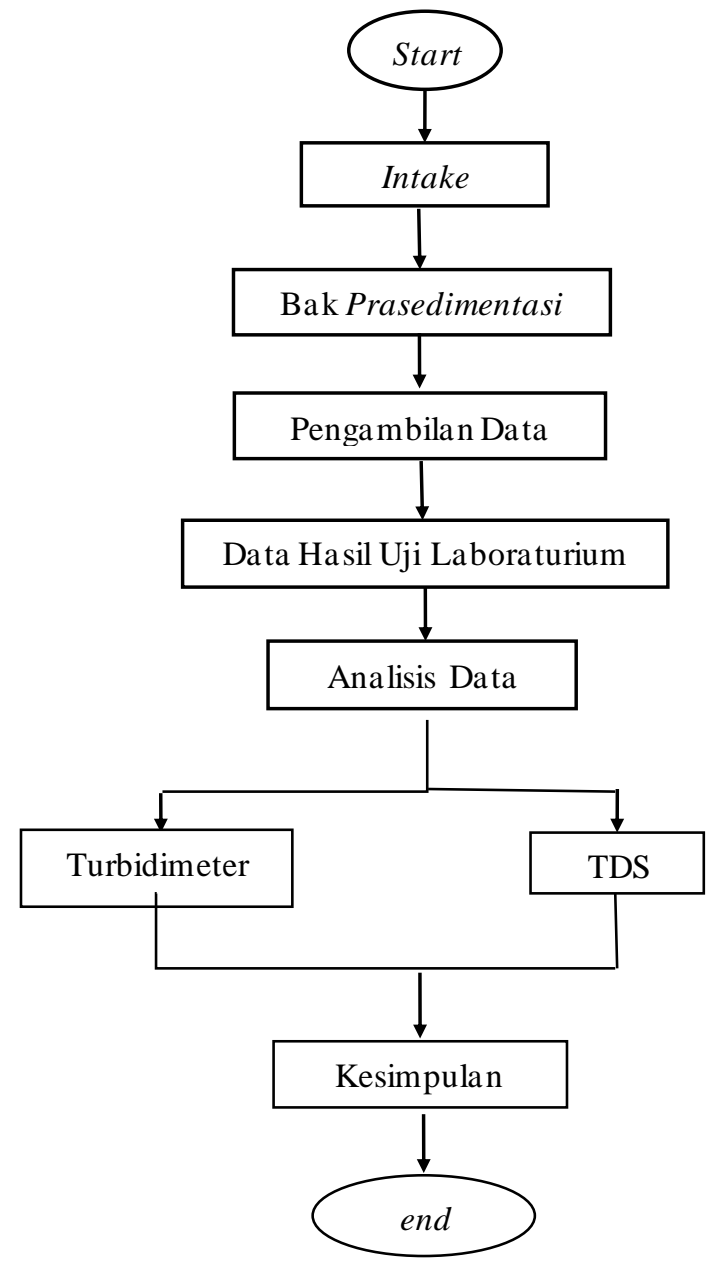

Gambar 1. Flowchart penga mbilan data pengaruh waktu pengendapan pada prasedimentasi air baku.

Dimulai dari pengambilan air baku yang diambil dari intake menuju bak prasedimentasi melalui pipa menggunakan jerigen kemudian dianalisis data dilaboraturium dan selesai.

Sampel air baku yang berasal dari sungai dibuat tiga kali pengujian supaya mendapatkan nilai yang spesifik. Air baku adalah sumber air yang bera sal dari a lam salah sa tunya yaitu air sungai. Air sungai terda pat kotoran seperti lumpur, batangbatang kayu, daun-daun, sesuai pada daerah air tersebut mengalir. Jenis kotorannya sepertikotoran fisika, kimia dan bakteri, sehingga akan dilakukan analisis a ir baku secara langsung di lapangan. Parameter kekeruhan dan TDS dilakukan uji laboraturium denga $n$ metode yang digunakan untuk mengukur para meter kekeruhan yaitu metode transmisicahaya den ga $n$ menggunakan alat turbidimeterdan metode mengukurTDS [3]. Parameter inilah yang menjadidasardalam pembuatan ala $t$ ukur TDS dan tingkat kekeruhan air (turbidimeter) [4].

Proses pengambilan data air akan diletakkan digelas ukur sebesar 1000 liter seba nyak 5 buah dengan sama rata. Setela h air baku sama rata akan dianalisis kualitas air dengan variasi waktu setiap 35 menit dari 0 sampai 125 menit. Hal ini untuk mengetahui waktu pengendapan air baku yang baik.

\section{HASIL DAN PEMBAHASAN}

Tabel 1 merupakan data hasil pengamatan, data yang diperoleh yaitu pengaruh kekeruhan dan TDS terhadap waktu sebelum dan sesudah pengendapan. Pengaruh kekeruhan kualitas sampel air baku sebelum dan sesudah dengan menggunakan a lat turbidimeter dan TDS. Dimana sampelair baku diuji sela ma 35 menit.

Air baku yang dapat dapat digunakan sebagai air minum, harus mengalamisuatu proses pengolahan yang ba ik, $\mathrm{k}$ a ren a mengingat bahwa air sungai pada umumnya mempunyai derajat kotoran yang tinggi sehingga diperlukan pengolahan air untuk dapat dikonsumsi masyarakat [5]. 
Insta lasi pengolahan air yang diproduksi untuk didistribusikan melalui unit-unit seperti intake untuk mengambil air dari sungai untuk menjaga kestabilan debit, kemudian diangkut oleh pompa ke tempat prasedimentasi. Bak prasedimentasi a ir yang berada dari intake akan ditampung untuk menurunkan partikel-partikel padat dariair sungai dengan sistem gra vitasi.

Tabel 1. Pengaruh kekeruhan dan TDS terhadap waktu

\begin{tabular}{|c|c|c|c|c|}
\hline \multirow{2}{*}{$\begin{array}{c}\text { Waktu } \\
\text { Pengendapan } \\
\text { (m) }\end{array}$} & \multicolumn{2}{|c|}{$\begin{array}{l}\text { Turbidimeter } \\
\text { (NTU) }\end{array}$} & \multicolumn{2}{|c|}{$\begin{array}{c}\text { TDS } \\
(\mathrm{Mg} / \mathrm{L})\end{array}$} \\
\hline & $\begin{array}{c}\text { Sebelum } \\
\text { Pengendapan }\end{array}$ & $\begin{array}{c}\text { Sesudah } \\
\text { Pengendapan }\end{array}$ & $\begin{array}{c}\text { Sebelum } \\
\text { Pengendapan }\end{array}$ & $\begin{array}{c}\text { Sesudah } \\
\text { Pengendapan }\end{array}$ \\
\hline $0-5$ & 20 & 20 & 93 & 93 \\
\hline $30-35$ & 20 & 16.1 & 93 & 92 \\
\hline $60-65$ & 20 & 15 & 93 & 91 \\
\hline $90-95$ & 20 & 14.4 & 93 & 91 \\
\hline $120-125$ & 20 & 13.9 & 93 & 90 \\
\hline
\end{tabular}

Dari data hasil pengamatan pada Tabel 1 waktu pengendapan sebelum dan sesudah pengendapan terhadap turbidimeter dan TDS air baku mengalami penurunan. Turbidimeter digunakan untuk mengukur kekeruhan dengan prinsip kerja alat tersebut menggunakan inesitas cahaya yang dibiaskan ke sampel hingga sampel terbaca kekeruhannya. Kekeruha n ini dipengaruhi oleh a danya bahan-bahan zat organik maupun non-organik yang halus, plakton, mikroorganisme serta suatu za t padat seperti ion, senyawa, dan koloid [6]. TDS (jumlah padatan logam terlarut) sebagai parameter dari jumlah partikel organik maupun non-organik. TDS ini terjadi karena adanya limbah rumah tangga, pelapukan dan limbah domestik serta efek partikel padatan terha dap keseha tan tergantung penyeb ab masalah yang terda pat pada spesies zat kimia [7].

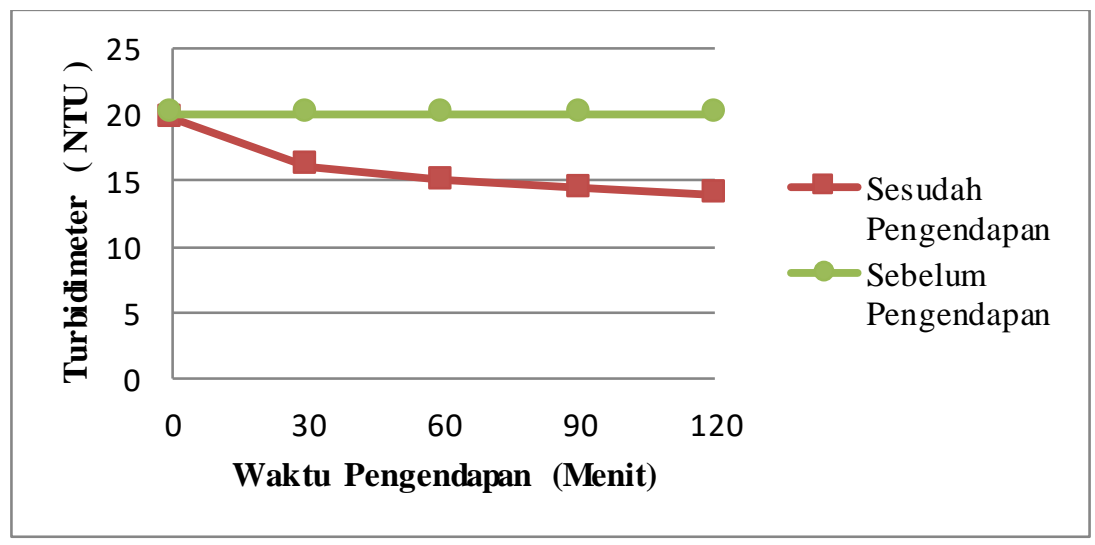

Grafik 1. Grafik pengendapan waktu terhadap kekeruhan air.

Pada Grafik 1 dapat dilihat bahwa waktu pengendapan air baku terhadap turbidimeter nilai sebelum pengendapan sebesar 20 NTU, pada saat sesudah pengendapan nilainya menurun dari 20 menjadi 13,9 NTU dengan rata - rata 3.9 sampai 0.3 NTU dalam waktu 0 - 120 menit. Hal tersebut dikarenakan air baku memiliki partikel halus yang massa jenisnya lebih berat dibandingkan dengan massa air. Oleh karena itu, semakin lama waktu pengendapan maka nilaiturbidimeter akan semakin menurun pula [8]. 


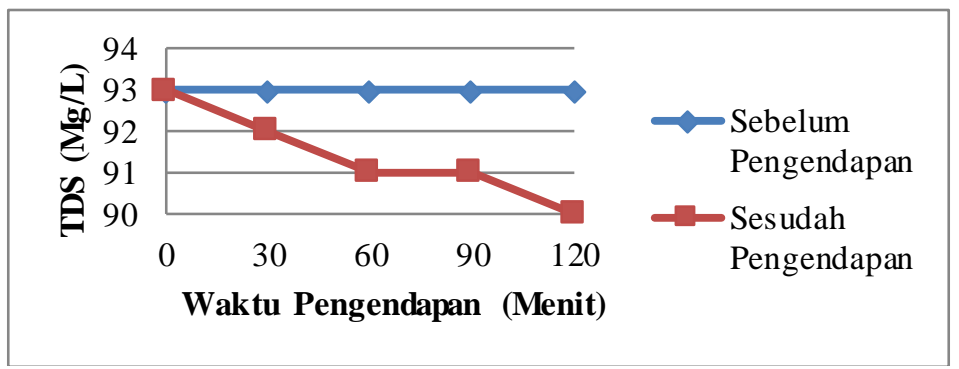

Grafik 2. Grafik pengendapan waktu terhadap TDS.

Pada Grafik 2 terlihat bahwa nilai TDS sebelum dan sesudah pengendapan memilikinilai sebesar $93 \mathrm{Mg} / \mathrm{L}$ dan $93-90$ $\mathrm{Mg} / \mathrm{L}$ dengan rata penurunan $1 \mathrm{Mg} / \mathrm{L}$. Hal ini dikarenakan TDS dalam air memiliki jumlah zat padatan terlarut yang berfungsi untuk mengukur jumlah ion dan hanya uji indikator kualitas air secara umum. Oleh karena itu, nilai TDS tergolong rendah, rendahnya nilaiTDS karena materialyang terlarut lebih sedikit [9].

Berdasarkan Peraturan Menteri Kesehatan Republik Indonesia No.492/Men.KES/PER/IV/2010 tentang baku mutu dan standar air minum dengan kadarkekeruhan pengendapan 0-125 menit yang paling baik yaitu pada waktu 125 menit den ga $n$ nilai yaitu 13,5 NTU dengan maksimalyang diperbolehkan yaitu 5 NTU, dalam penga matan ini waktu nilai TDS sebesar 90 $\mathrm{Mg} / \mathrm{L}$, sedangkan untuk kadarTDS maksimaldiperbolehkan yaitu $500 \mathrm{Mg} / \mathrm{L}$ sehingga penga matan air baku perlu dilakukan lebih lanjut untuk layak digunakan.

\section{KESIMPULAN}

Kesimpulan yang diperoleh dari penelitian ini adalah:

1.Adapun waktu mengendapan air baku pada 0-120 menit sebesar 20-13,9 NTU dengan TDS dari 93-90 Mg/L menga lami penurunan karena dipengaruhipartikel yang memiliki massa jenis yang berat dibandingkan massa jenis air.

2.Berdasarkan dari alat turbidimeter dan TDS kualitas air baku yang baik digunakan setelah pengendapan yaitu selama 120 menit dengan kualitas 13,9 dengan nilai TDS sebesar $90 \mathrm{Mg} / \mathrm{L}$.

\section{DAFTAR PUSTAKA}

[1] T. R. Trias Kembara, "OPTIMALISASI INSTALASI PENGOLAHAN AIR (IPA ) PDAM TIRTA DAROY KOTA BANDA ACEH TERHADAP TINGKAT KEKERUHAN," 2018.

[2] N. F. Arifiani dan M. Hadiwidodo, "Evaluasi Desa in Instalasi Pengolahan Air Pdam Ibu Kota Kecamatan Prambanan Kabupaten Klaten," J. Presipitasi, vol. 3, no. 2, hal. 78-85, 2007, doi: 10.14710/presipita si.v3i2.78-85.

[3] D. B. Rejo, K. T. Seberang, dan T. S. Sub-district, "Analisa Tingkat Pencemaran Air pada Sumur Gali Analysis of Water Pollution Level in Dug Well RT 15, Bangun Rejo Village ,” vol. 15, no. 02, hal. 31-36, 2019.

[4] R. P. Wirman, I. Wardhana, dan V. A. Isnaini, "Kajian Tingkat Akura si Sensor pada Rancang Bangun Alat Ukur TotalDissolved Solids (TDS) dan Tingkat Kekeruhan Air," J. Fis., vol. 9, no. 1, hal. 37-46, 2019, doi: 10.15294/jf.v9i1.17056.

[5] F. Majid, "Pasir, Zeolit dan Arang Aktif Sebagai Media Filtrasi untuk Menurunkan Kekeruhan, TDS dan E-Coli Air Selokan Mataram Yogyakarta," Kesehat.Lingkung., hal. 15-41,2019, [Daring]. Tersedia pada: http://eprints.poltekkesjogja.ac.id/id/eprint/877.

[6] B. Yuniarti, "PENGUKURAN TINGKAT KEKERUHAN AIR MENGGUNAKAN TURBIDIMETER BERDASARKAN PRINSIP HAMBURAN CAHAYA," Skripsi, vol. 3, no. September, 2007.

[7] F. Nicola, "HUBUNGAN ANTARA KONDUKTIVITAS, TDS (TotalDissolved Solid)," Skripsi, hal. 1-61, 2015, [Daring]. Tersedia pada:http://repository.unej.ac.id/bitstream/handle/123456789/73766/prosiding-snk2015-hal-isi159-164_MIPA.pdf?sequence=2.

[8] M. Pandu dan J. Ampera, "Penurunan Kekeruhan Air Baku Ipa Badak Singa Dengan Penggunaan Koagulan Pac Dan Plat Alumunium Pada Proses Koagulasi- Elektrokoagulasi Dengan Penggunaan Koagulan Pac Dan Plat Alumunium Pada Proses Koagulasi-," 2018.

[9] Rinawati, D. Hidayat, R. Suprianto, dan P. Dewi, "Penentuan Kandungan Zat Padat ( Total Dissolve Solid Dan Total Suspended Solid ) Di Perairan Teluk Lampung," Anal. Environ. Chem., vol. 1, no. 01, hal. 36-45, 2016, [Daring]. Tersedia pada: http://repository.lppm.unila.ac.id/2831/1/Volume 1_Hal36-45-Rina.pdf. 